\title{
Genetic similarity among Caesalpinia echinata trees and their ex situ conservation
}

\author{
Fernanda Barbosa Cupertino, Sônia Cristina Oliveira Melo and Ronan Xavier Corrêa* \\ Departamento de Ciências Biológicas, Universidade Estadual de Santa Cruz, Rodovia llhéus-Itabuna, km16, \\ Salobrinho, Ilhéus, Bahia, Brasil. CEP: 45662-000.
}

Accepted 27 July, 2013

\begin{abstract}
Brazilwood (Caesalpinia echinata Lam) is a tree native to the Atlantic rainforest. It has been exploited since the Brazilian colonial period and the remaining natural populations of $C$. echinata have been reduced to small forest fragments, or are conserved in arboreta and ecological parks. This study aimed to identify the degree of genetic diversity present within brazilwood trees from three different sites in southern Bahia State, through random amplified polymorphic DNA (RAPD) markers and discuss criteria to enrich an ex situ conservation area in the campus of the Universidade Estadual de Santa Cruz, Brazil. Out of the 53 primers tested, 16 revealed 38 reproducible polymorphic and good quality bands. The similarity coefficients among individuals varied from 0.43 to 1.00 . The average similarity coefficients were higher in ex situ collections $(0.82$ to 0.70$)$ than in situ region (0.46). The UPGMA analysis displayed the formation of three distinct groups, although the similarity among all accessions was high (around $70 \%$ ). The conservation of plant species away from their natural habitat needs to be done carefully, with the introduction of individuals that offer the highest level of genetic diversity possible and contribute to the biological preservation of the species.
\end{abstract}

Key words: Pernambuco, Ibirapitanga, tropical tree, genetics conservation, molecular markers, biodiversity, endangered flora.

\section{INTRODUCTION}

Caesalpinia echinata Lam. 1785 (Fabaceae: Caesalpinioideae) is known as brazilwood or Pernambuco wood, and is native to the Atlantic Forest of Brazil, although it has also been shown to be extremely fragile (Lima, 2002). The Brazilian Atlantic Forest is one of the most genetically and biologically diverse ecosystems on earth, and is among the eight hottest hotspots of biodiversity for conservation priorities in terms of five factors related to species endemism (Myers et al., 2000). Before the Portuguese colonization, brazilwood occurred along the Brazilian Atlantic Coast between Rio Grande do Norte and Rio de Janeiro States (Lima, 1992). In the past 30 years, the occurrence of remnant popu- lations has been confirmed in Rio Grande do Norte, Paraíba, Pernambuco, Alagoas, Bahia, Espírito Santo, Rio de Janeiro and São Paulo States (Lima, 1992). However, these populations are small and mostly located in southern Bahia State. This reduction in population size can cause loss of alleles and, consequently, increase genetic similarity in subsequent generations.

One of the first economic activities during the colonization of the Brazilian territory, between 1500 and 1822, was the intense exploitation of $C$. echinata for its wood, generating extensive wealth for the Portuguese government. Brazilwood, being hard, heavy and replete with pigments (Brazilin and Brazilein), was used in civil 


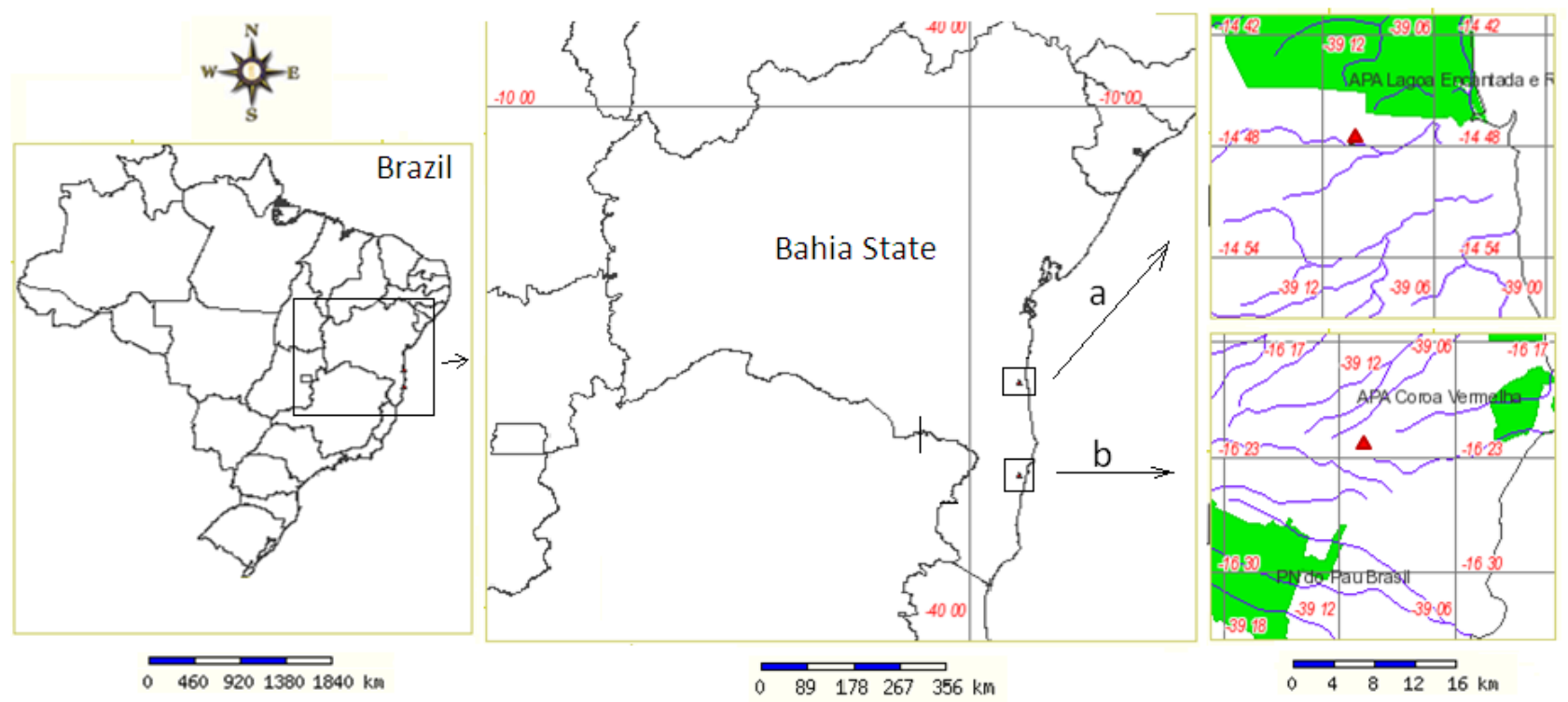

Figure 1. Map showing the brazilwood collection sites $(\mathbf{\Delta})$. The green zones are permanent protected areas. The blue lines are different rivers. The dark lines are interstate divisions. Arrow correspondes to sites (a) Forest and Arboretum of Universidade Estadual de Santa Cruz (Ilhéus), and (b) Estação Ecológica Pau-Brasil (Porto Seguro).

and naval industries, in addition to the dyeing of cloth and ink production (Oliveira et al., 2002).

Today, brazilwood is exported in small quantities for the production of musical instruments, especially violin bows (Bueno, 2002). A current use of native trees for afforestation of large cities is seen as an alternative to enhance the people's know-ledge on the tree species, mainly endangered ones. New urban generations of people may become aware of the richness of biodiversity more effectively. Additionally, it would be a complementary form of conservation of biodiversity (Rocha and Barbedo, 2008).

C. echinata has suffered from degradation of its natural habitat (the Atlantic Forest) and constant urban growth (Melo-Filho, 1991, 1992; Cardoso et al., 1998; Bueno, 2002), resulting in the isolation of remnant trees in small forest fragments and in a diminished scale of natural reproduction. As a consequence, brazilwood was classified as threatened with extinction by the Brazilian Institute of the Environment and Amazon (IBAMA) in 1992. This species is also included in the IUCN Red List of Threatened Species as "endangered" (Varty, 1998).

Genetic studies of brazilwood have been scarce, but Cardoso et al. (2005) demonstrated the existence of genetic structure which may be mainly due to forest fragmentation. This information is useful for the development of conservation plans, such as indication of conservation unit size, which populations should be chosen as priority, and which samples should be introduced in areas with a low number of individuals of brazilwood. Therefore, strate-gies to maintain and enlarge the genetic diversity of $C$. echinata are important to protect the in situ popu- lations by preserving the trees in their natural habitat, allowing environmental interaction and the continuation of genetic variability. These studies are also important for the conservation of ex situ populations in arboreta, ecological parks and/or active germoplasm banks, using native species seed technology.

In this study, we aim to study the genetic diversity of $C$. echinata conserved ex situ in southern Bahia State, using a battery of random amplified polymorphic DNA (RAPD) markers (Williams et al., 1990). We calculated the genetic similarity coefficients among plants and showed their relationships through UPGMA analysis. We demonstrated the necessity of enrichment of the ex situ conservation areas, by means of a comparison with the genetic diversity verified in a sample of trees from an in situ conservation site.

\section{MATERIALS AND METHODS}

\section{Plant material and DNA extraction}

Leaf samples of $32 C$. echinata plants were collected in southern Bahia (Figure 1) and divided into three groups according to their location (Table 1). $50 \%$ of the trees inventoried in each of these areas were randomly taken. The Arboretum (PBARB) of Universidade Estadual de Santa Cruz (UESC), Ilhéus was implanted in 2000. It is located continuously with an area of 20 ha of regeneration rainforest (PBUESC) in the last 20 years. In 1990s, this area was enriched with about 20 plants of brazilwood. The seedlings are from neighboring forest fragments, but the exact location of seed collection or parental control is not known.

The PBARB and PBUESC were chosen because they are located within the campus of UESC and represent a consistent way 
Table 1. Location, plant conservation type, number of samples collected ( $n$ ) and identification of the sample numbers (ident.).

\begin{tabular}{llcc}
\hline Group & Location (South of Bahia) & Conservation & n (ident.) \\
\hline PBARB & $\begin{array}{l}\text { Arboretum of Universidade Estadual de Santa Cruz (UESC), } \\
\text { latitude 14.7942, longitude -39.1740, llhéus }\end{array}$ & ex situ & $17(1-17)$ \\
PBUESC & $\begin{array}{l}\text { Forest of Universidade Estadual de Santa Cruz (UESC), } \\
\text { latitude 14.7955, longitude -39.1720, llhéus }\end{array}$ & ex situ & 08 (18-25) \\
ESPAB & $\begin{array}{l}\text { Forest of Estação Ecológica Pau-brasil (ESPAB), latitude } \\
16.3883, \text { longitude -39.1819, Porto Seguro }\end{array}$ & in situ & 07 (26-32) \\
\hline
\end{tabular}

Table 2. Sequences of the selected primers, size range and number of the amplified bands and number of polymorphic bands.

\begin{tabular}{llccc}
\hline Primer & Sequence & Band size (bp) & Total of bands & Polymorphic bands \\
\hline OPA01 & 5'-CAGGSSSTTC-3' & $493-1375$ & 5 & 2 \\
OPA11 & 5'-CAATCGCCGT-3' & $125-1584$ & 5 & 1 \\
OPA20 & 5'-GTTGCGATCC-3' & $493-2027$ & 6 & 3 \\
OPB01 & 5'-GTTTCGCTCC-3' & $125-2752$ & 7 & 3 \\
OPB08 & 5'-GTCCACCAGG-3' & $125-2027$ & 4 & 1 \\
OPC16 & 5'-CACCATCCAG-3' & $493-1120$ & 5 & 2 \\
OPC20 & 5'-ACTTCGCCAC-3' & $125-1584$ & 6 & 1 \\
OPD03 & 5'-GTCGCCGTCA-3' & $493-1584$ & 5 & 3 \\
OPE01 & 5'-CCCAAGGTCC-3' & $493-1120$ & 5 & 1 \\
OPE11 & 5'-GCGTCTTAGG-3' & $493-2027$ & 12 & 10 \\
OPF06 & 5'-GGGAATTCGG-3' & $125-784$ & 4 & 2 \\
OPF10 & 5'-GGAAGCTTGG-3' & $125-831$ & 4 & 2 \\
OPI01 5 5'-ACCTGGACAC-3' & $784-1584$ & 5 & 1 \\
OPI13 & 5'-CTGGGGCTGA-3' & $784-1584$ & 5 & 2 \\
OPK07 & 5'-AGCGAGCAAG-3' & $125-1120$ & 6 & 2 \\
OPL01 & 5'-GGCATGACCT-3' & $483-1584$ & 5 & 2 \\
Total & & - & 89 & 38 \\
\hline
\end{tabular}

to maintain indefinitely the botanical material for teaching purposes, scientific research and conservation of genetic diversity. Courses and regular disciplines can use these two sites for demonstration classes on strategies for ex-situ conservation. The gradual enrichment of the forest with different accessions of brazilwood from nearby areas can be monitored using molecular markers. It will also serve to demonstrate the different stages of forest restoration, since this campus was a plantation of cacao until the 1980s.

The Estação Ecológica Pau-Brasil (ESPAB) is a natural rainforest, conserved for about 50 years, in Porto Seguro. We accessed a subarea of 20 ha inside this forest (1145 ha). The genotypes from this area were used in this study as a hypothetical reference of diversity and a potential source of material for enrichment of ex situ conservation sites.

Leaves were stored at $-80^{\circ} \mathrm{C}$ and the DNA was extracted by the CTAB method proposed by Doyle and Doyle (1987), modified by the addition of PVP and proteinase $\mathrm{K}$ extraction buffer, and by the reduction of the amount of leaves used in the extraction protocol (Freire et al., 2007).

\section{DNA Amplification by PCR-RAPD}

Fifty-three random primers (Primer Operon Tecnologies, CA) were used for the DNA amplification. But, we used in the analysis only 16 primers selected according to the reproducibility and clarity of the bands (Table 2 ).

The total volume of the reaction was $25 \mu \mathrm{L}$, and consisted of 50 mmol. $\mathrm{L}^{-1} \mathrm{KCl}, 10 \mathrm{mmol} . \mathrm{L}^{-1}$ Tris- $\mathrm{HCl}, 2.4 \mathrm{mmol} . \mathrm{L}^{-1} \mathrm{MgC}_{2}, 0.1$ mmol. $\mathrm{L}^{-1} \mathrm{dNTPs}, 0.4 \mu \mathrm{mol} . \mathrm{L}^{-1}$ of primer, $1 \mathrm{U}$ of Taq polimerase and $5 \mathrm{ng} / \mu \mathrm{L}$ of DNA. DNA amplification was performed using a GeneAmp PCR System 9600 (Applied Biosystems, CA) with the following conditions: a first step of $94^{\circ} \mathrm{C}$ for $1 \mathrm{~min} ; 40$ cycles of $94^{\circ} \mathrm{C}$ for $15 \mathrm{~s}, 35^{\circ} \mathrm{C}$ for $30 \mathrm{~s}$ and $70^{\circ} \mathrm{C}$ for $1 \mathrm{~min} ; 1$ cycle of $72^{\circ} \mathrm{C}$ for 7 min. The amplified products were analyzed by electrophoresis in $1.2 \%$ agarose gels containing ethidium bromide. Gel images were captured by EDAS 290 systems (Kodak). The sizes of the fragments were visually compared to a $\lambda$ fago ladder digested with EcoRI, Hindlll and BamHI endonucleases.

\section{Genetic analysis}

The reproducibility of the amplification products was tested for each of the primers used in the experiments. Only equivalent standard products that were amplified by two different people were considered. Data analyses were performed through binary variables represented by presence (1) or absence (0) of clear and reproducible bands observed on the agarose gels. The phenotypic gene diversity $\left(H_{p}\right)$ was estimated for each locus, and the mean over all loci at different locals of collection was quantified, according to Mariette et al. (2002).

Genetic similarity coefficient calculations among the accessions and the UPGMA analysis were preformed by the Dice method ( $\mathrm{Nei}$ and Li, 1979), using the NTSYS v.1.70 software (Rohlf, 1992). The cophenetic value $(r)$ was calculated by the $\mathrm{COPH}$ program from the 


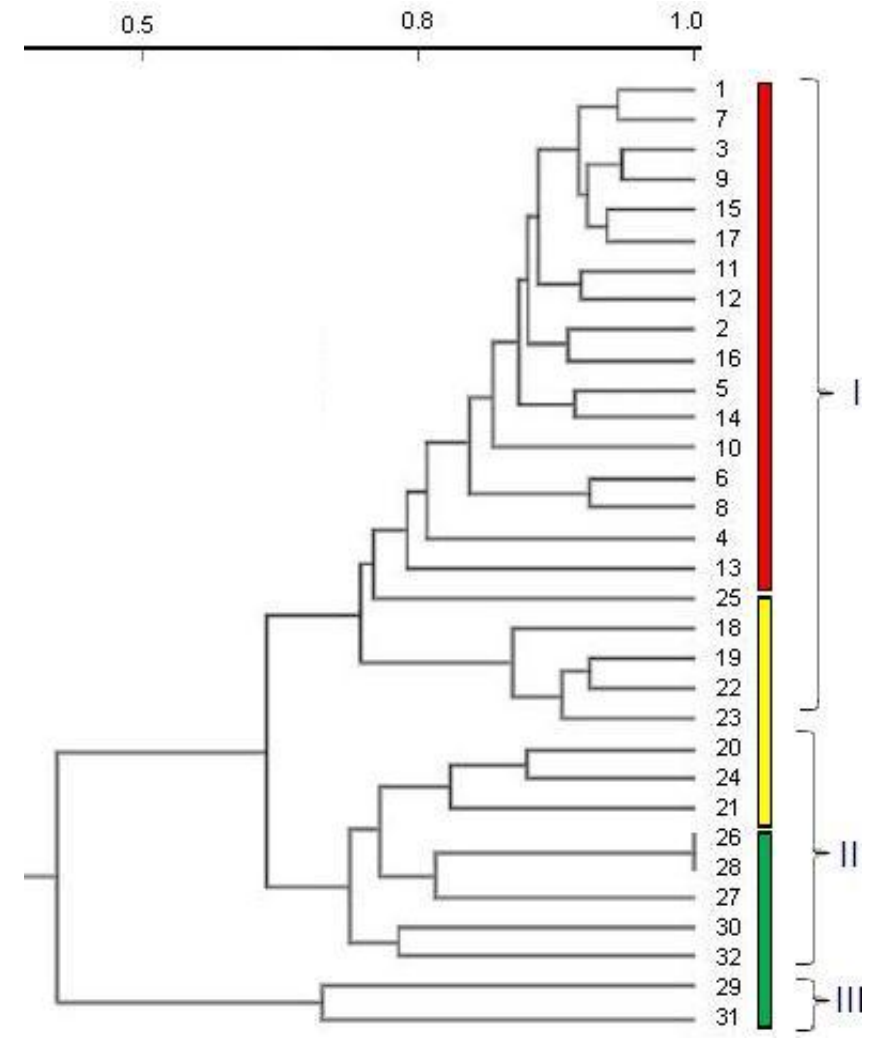

Figure 2. UPGMA dendrogram constructed from a genetic similarity coefficient among individuals. Bars represent the Individuals according to their origin as described in Table 1: 1 to 17 (PBARB); 18 to 25 (PBUESC); and 26 to 32 (ESPAB). Diversity Groups I, II and III are formed from a threshold of 0.7 of similarity coefficient.

Table 3. Estimates of genetic similarity coefficient (Sij) and its coefficient of variation (cv), mathematical complement of Sij (Dij), phenotypic gene diversity $\left(H_{p}\right)$ of three different groups of $C$. echinata based on RAPD markers.

\begin{tabular}{lcccc}
\hline Group & Sij & cv & Dij & Hp \\
\hline PBARB & 0.8239 & 0.0040 & 0.1761 & 0.4820 \\
PBUESC & 0.6984 & 0.0145 & 0.3016 & 0.4688 \\
ESPAB & 0.4581 & 0.0414 & 0.5419 & 0.4158 \\
\hline
\end{tabular}

NTSYS software. The cophenetic value matrix was then employed to check the validity of the fit to the cluster analysis by comparing it with the original similarity matrix. As a complement, the average similarity of plants sampled at each site was calculated.

\section{RESULTS}

The random primers amplified multiple bands ranging in size from 125 to 2752 bp. Any primers that showed different band reproduction standards were immediately discarded. A total of 38 bands, out of 89 , were polymorphic and showed good quality, and were used in the analysis (Table 2).

The cluster analysis permited the analysis of the relationship among $C$. echinata individuals (Figure 2). Three distinct groups were produced by the UPGMA analysis. The first group consisted of all 17 arboretum plants (PBARB) and some individuals from the UESC forest (PBUESC). The second group was formed by some plants from PBUESC forest and some from the ESPAB forest. The third group was made up of two individuals from ESPAB. The cophenetic value was significantly high $(r=0.87)$ and a measure of the validity (goodness) of fit to the cluster analysis.

Similarity coefficients among the samples varied from 0.431 to 1.0 (data not show) and allow the identification of three different groups of plants (Figure 2). The group I was composed of plants from PBARB and some from PBUESC, and show high levels of similarity among individuals. The group II was formed by some plants from PBUESC and someone from ESPAB, which show intermediary levels of similarity among individuals. On the other hand, in group III, individuals 29 and 31 showed the lowest genetic similarity coefficients as compared to other plants, which show the relationship among the $C$. echinata plants from ESPAB. Among all plants, individuals 26 and 28 from ESPAB were the most similar, showing $100 \%$ similarity.

The mean genetic similarity of plants at each site varied between the three sampled sites, as well as the estimated values of $\mathrm{Hp}$ (Table 3). The complement of the mean genetic similarity reveals different levels of diversity among groups of plants regarding its origin.

\section{DISCUSSION}

The present study aimed to show the genetic similarity of brazilwood plants from three different places using RAPD-based markers. The majority of brazilwood individuals analyzed in this study showed a genetic similarity, in spite of the formation of three distinct groups (Figure 2). The genetic similarity of trees conserved ex situ was compared with a sample of trees from an in situ conservation site. The PBARB individuals, numbered from 1 to 17, formed a homogeneous group, suggesting the possibility of common parentage. Plants collected at ESPAB (numbered from 26 to 32) were more genetically varied than the PBARB and PBUESC samples, and revealed the lowest similarity coefficients. Plants conserved ex situ revealed coefficients of similarity larger than those observed in ESPAB. Although cluster analysis has not coincided perfectly with the places of origin, the mathematical complement of similarity coefficient reveal greater genetic diversity among materials from ESPAB in relation to others (Table 3). All together, these results are in accordance with the history of the arboretum and forest of UESC, where seedlings from the southern region of 
Bahia State were introduced some years ago, probably collected from a small number of plants. This may explain the low genetic diversity of the samples from the ex situ conservation studied areas.

The formation of closely related familiar structures among individuals located in close proximity within population units may be a result of the reduction of population or subpopulation size. The occurrence of reduced genetic variability, mainly caused by inbreeding and genetic drift, is common in small islands. Together, these factors can result in the depression of the species genetic composition (Frankham, 2003), as seen in the intensive historical exploitation of the brazilwood trees.

The reduction of genetic variability in $C$. echinata has been reported by Cardoso et al. (1998) and Lira et al. (2003) for populations in Rio de Janeiro, Espírito Santo and Bahia States. However, we have found high genetic diversity in Porto Seguro and Jussarí (BA) populations, despite the reported loss of allele wealth due to drift and inbreeding effects (data not published). For the conservation of plant species, it is important to be able to recognize the varying genotypes of different individuals to monitor the reintroduction of populations. This is especially important considering the reproduction mechanism of $C$. echinata, which has low seed dispersion (Lira et al., 2003).

Genetic variability analysis with RAPD markers has already been performed on exotic tree species, including Eucalyptus (Chunyang, 2000) and Pinus (Peng et al., 2003). In addition, a genetic diversity and structure analysis has been performed in an ex situ population of C. echinata with isoenzimatic markers by Giudice-Neto et al. (2005). Other wild species of Fabaceae have also been analyzed using RAPD (Jena et al., 2004; Freire et al., 2007) and isoenzyme markers (Sotuyo et al., 2004) in genetic diversity studies. The high taxomic complexity of Caesalpinioideae has been studied with the aid of the RAPD markers (Tripathi and Goswami, 2011).

One current use for molecular markers is numerically demonstrating the need for genetic conservation and assist in the structuring of the conservation plan. Gandara and Kageyama (1998) defined indexes as monitoring the changes caused by anthropic activities in forestry. These indexes include richness of tree species, genetic diversity within populations and indicator species. So, regarding genetic diversity, our study on the genetic similarity of brasilwood individuals (a rare plant species) is an important criterion to be observed in monitoring the conservation areas. When inspecting the dendrogram, materials with lower values of genetic similarity are from groups II and III (Figure 2). Therefore, these materials should be used to enrich the ex situ collections of UESC (only 26 or 28 materials could be dispensed). Future studies with these three integrated criteria can demonstrate the usefulness of demographic and genetic parameters for the restoration and maintenance of diversity and ecological processes in ex situ conservation initiatives.

The introduction of genotypes from the ESPAB can improve the genetic diversity in the conservation area of brazilwood in UESC. However, it can be inferred that due to high genetic structure in the remaining populations of brazilwood (Cardoso et al., 2005), the plan to enrich this area of ex situ conservation should include genotypes from other sites of natural occurrence of the species. The maximizing genetic effective size, and therefore the variability, can be achieved by conducting intensive surveys in various populations within regions (Giudice Neto et al., 2005). But, due the divergence between the regions of occurrence of $C$. echinata, we need to improve the different ex situ collection with genotypes from similar regions, to obtain representation of different evolutionary processes that occurred in different regions. These depict the need of multiple-site of ex situ conservation in complementation of the in situ conservation programs.

The maintaining of species ex situ needs to consider the degree of variability of the plants to be reintroduced within a given area, even brazilwood in the arboretum of UESC. So, we recommend improving this arboretum with introduction of more distantly related plants, from different natural sites around similar ecological sites. This improvement can transform this arboretum into an effective conservation site, which is devoted to conserve Atlantic forest trees. The use of accessions or seedlings with high genetic diversity is the best option for reintroduction in degraded area restoration program, and in the creation of germplasm banks, ensuring the maximum representation of diversity among accessions and the effective biological conservation of the genetic variability of the species.

\section{REFERENCES}

Bueno $E$ (2002). Nova viagem à terra do pau-brasil. In: Bueno E. (ed), Pau-brasil. Axis Mundi, São Paulo. pp. 39-76.

Cardoso MA, Provan J, Powell W, Ferreira PCG, Oliveira DE (1998). High genetic differentiation among remnant populations of the endangered Caesalpinia echinata Lam. Mol. Ecol. 7:601-608.

Cardoso SRS, Provan J, Lira CF, Pereira LOR, Ferreira PCG, Cardoso MA (2005). High levels of genetic structuring as a result of population fragmentation in the tropical tree species Caesalpinia echinata Lam. Biodivers. Conserv. 14:1047-1057.

Chunyang $L$ (2000). RAPD analysis of genetic variation in Eucalyptus microtheca F. Muell. populations. Hereditas. 132:151-156.

Doyle JJ, Doyle JL (1987). Isolation of plant DNA from fresh tissue. Focus 12:13-15.

Frankham R (2003). Genetics and conservation biology. C. R. Biologies 326: $22-29$

Freire JM, Piña-Rodrigues FCM, Lima ER, Sodré SRC, Corrêa RX (2007). Genetic structure of Schizolobium parahyba (Vell.) Blake (guapuruvu) populations by RAPD markers. Sci. For. 74:27-35.

Gandara FB, Kageyama PY (1998). Indicators for the sustainability of natural forests. Série Téc. IPEF. 12:79-84.

Giudice-Neto JD, Sebbenn AM, Kageyama PY (2005). Genetic diversity of ex situ populations of Caesalpinia echinata Lam. Sci. Flor. 69: 125133

Jena S, Sahoo P, Mohanty S, Das AB (2004). Identification of RAPD markers, in situ DNA content and structural chromosomal diversity in some legumes of the mangrove flora of Orissa. Genetica 122:217-226. 
Lima HC (1992). Aspectos botânicos do pau-brasil. In: Cunha, M. W. and Lima, H. C. (eds.), Viagem à terra do pau-brasil. Agência Brasileira de Cultura, Rio de Janeiro. pp. 23-38.

Lima HC, Lewis GP, Bueno E (2002). Pau-brasil: uma biografia. In: Bueno E (ed). Pau-brasil. Axis Mundi, São Paulo. pp. 39-76.

Lira CF, Cardoso SRS, Ferreira PCG, Cardoso MA, Provan J (2003). Long-term population isolation in the endangered tropical tree species Caesalpinia echinata Lam. revealed by chloroplast microsatellites. Mol. Ecol. 12:3219-3225.

Mariette S, Le CV, Austerlitz F, Kremer A (2002) Sampling within the genome for measuring within-population diversity: trade-offs between markers. Mol. Ecol. 11:1145-156.

Melo-Filho LE (1991/1992). A Floresta Atlântica. In: Monteiro, S. and Kaz, L. (eds.), Floresta Atlântica: Textos Científicos. Alumbramento, Rio de Janeiro, p.17-21.

Myers N, Mittermeier RA, Mittermeier CG, Fonseca G, Kent J (2000) Biodiversity hotspots for conservation priorities. Nature 403:853-858

Nei M, Li WH (1979). Mathematical model for studying genetic variations in terms of restriction endonucleases. Proc. Natl. Acad Sci. USA. 76:5269-5273.

Peng SL, Li QF, Wang CF, Wang DP (2003). Genetic diversity of Pinus massoniana revealed by RAPD markers. Silvae Genetica 52: 60-63.
Rocha YT, Barbedo ASC. (2008) Pau-Brasil (Caesalpinia echinata Lam., Leguminosae) na arborização urbana de São Paulo (SP), Rio de Janeiro (RJ) e Recife (PE). Rev. SBAU. 3:58-77.

Rohlf FJ (1992). NTSYS: Numerical taxonomy and multivariate analysis system, Version 1.7. Applied Biostatistics Inc, New York.

Sotuyo S, Contreras JL, Delgado-Salinas A, Oyama K (2004). Genetic diversity and structure of the endemic Caesalpinia hintonii complex (Leguminosae: Caesalpinioideae) in México. Plant Syst. Evol. 247:131-143.

Tripathi V, Goswami S (2011). Generic relationship among Cassia L., Senna Mill. and Chamaecrista Moench using RAPD markers. Int. J. Biodivers. Conserv. 3(3): 92-100.

Varty N (1998). Caesalpinia echinata. In: IUCN2006. 2006 IUCN Red List of Threatened Species. www.iucnredlist.org. Downloaded on july $15^{\text {th }}, 2006$.

Williams JGK, Kubelik AR, Livak KJ, Rafalski JA, Tingey SV (1990). DNA polymorphisms amplified by arbitrary primers are useful as genetic markers. Nucleic Acids Res. 18: 6531-6535. 